\title{
Dementia and the Politics of Memory in Fiction. From the Condition as Narrative Experiment to the Patient as Plot Device
}

This essay historically situates dementia fiction of the early 2000s that features Alzheimer's disease or a similar type of dementia in the context of the Second World War and the Holocaust. ${ }^{1}$ It will delineate shifts that have occurred in how dementia is deployed in fiction that negotiates the various crimes committed and traumas predominantly caused by Nazi Germany. To do this, it will focus on the period from the 1980s onwards, commonly referred to as "Alzheimerisation" (Adelman 1995), when literary writing first employed the term "Alzheimer's disease." The period between 1980 and today is not distant enough to offer truly historicist conclusions. But to my mind, we can distinguish different phases of dementia literary writing (including significant periods of overlap), especially regarding how memory and forgetting have been explored and deployed in bestselling dementia fiction. I would distinguish: (i) literary fiction of the 1980s developed during what Jens Brockmeier (2015) refers to as the "memory boom" and Andreas Huyssen (2003, 4) sees as marked by an "explosion of memory discourses"; (ii) literary lifewriting by dementia caregivers of the 1990s as part of the continuation of the memory boom period; and (iii) bestselling literary fiction of the early 2000 s.

This essay brings a fictional text from the 1980s into conversation with several titles of the new century (for reflections on literary life-writing, I point to the contributions by Kristina Lucenko, Nina Schmidt and Dana Walrath in this volume). I take Debra Dean's bestseller The Madonnas of Leningrad (2006) and Alice LaPlante's acclaimed Turn of Mind (2011) as my present-day examples and read them against J. Bernlef's bestselling novel Out of Mind, first published in

\footnotetext{
1 An early version of this essay was conceived as a contribution to the conference "Dementia, Violence, and the Politics of Memory in Contemporary Literature, Film, and Comics," Freie Universität Berlin, in September 2018. A revised and expanded version was presented at a Centre for the Humanities and Health seminar, King's College London, in January 2019. Different parts of it were shared at the "Conversations on Care and/in the Community" workshop at Birkbeck, University of London, in June 2019, and during the "Ageing, Illness, Care” conference at the University of Huddersfield, in September 2019. I am grateful for the engaged and inspirational discussions which added to the revision of this essay in its final form. But most of all I owe sincerest thanks to Irmela Marei Krüger-Fürhoff, Nina Schmidt and Sue Vice for the invitation to Berlin and their generous editorial input throughout. I am funded by a UK Research and Innovation Future Leaders Fellowship (MR/T019794/1).
}

Ә Open Access. (๖) 2022 Martina Zimmermann, published by De Gruyter. (cc) BY-NC-ND This work is licensed under the Creative Commons Attribution-NonCommercial-NoDerivatives 4.0 International License. 
Dutch as Hersenschimmen in 1984 and translated into English four years later. Within the period of Alzheimerisation, Out of Mind is arguably the first fictional text that melded the experience of dementia with the Nazi horror: dementia equals a death sentence and removes agency from the patient. This essay will explore how The Madonnas of Leningrad and Turn of Mind build on this move to connect dementia to cultural memory. Beyond that, it will question the possibilities of linguistic characterisation, narrative perspective and implied readerly activity (by which I mean empathy and reading for the plot) to release the patient from such imagery and lack of agency.

Over the period under investigation, studies concerned with the language of dementia patients significantly shifted in focus, and I will explore how literary representations resonate with these changing linguistic approaches, how remembering and forgetting are explored as tied to language use. Early psycholinguistic studies particularly concentrated on language breakdown, i.e. the deterioration of linguistic skills, explained by worsening cognitive skills. Since around the mid-1990s, interest has gradually shifted towards sociolinguistic dimensions. These sociolinguistic studies emphasise patients' continued linguistic capabilities and agency, assigning an important role to context in dementia discourse. $^{2}$ My readings take context as the space and atmosphere in which the patient remembers. I will trace how the situated interaction between patient and caregiver in fictional representations follows the gradual shift from psycho- to sociolinguistic perspectives. In addition, I will look at the role of cultural memory in each text and ask how its presence relates to a character's continued agency and maps onto language breakdown.

The memories explored in this essay concern the Nazi horror in Out of Mind and The Madonnas of Leningrad and an evil crime committed in Turn of Mind. Why read these novels together? In each text, the patient's disease-imposed forgetfulness is played out against salvation - deliverance from the disease, acknowledgement of the patient's inner life, redemption of the criminal. Their melodramatic turn makes us read for the plot and invest in their patient-narrators (Brooks 1995). But each text exemplifies a different understanding of dementia. Out of Mind can be taken as a linguistic study of the condition as embodying decline and loss. The Madonnas of Leningrad also develops dementia as a condition of dispossession, but its alternating narrative perspective draws the reader into an awareness of the patient's continued inner life. Turn of Mind, in the style of Henry James's novella The Turn of the Screw (1898), to which the detective story's title alludes, plays on

2 Vai Ramanathan (1997, Ch. 1) offers an excellent overview of the developments outlined in this paragraph. 
the reader's belief in the patient's continued capabilities (Brooks 1995, 166-167). LaPlante challenges notions of loss as she creates a patient on whose lasting agency and memory the reader relies to find out whodunit.

Finally, the nexus of cultural memory, care environment and patient agency in bestselling writing points to one further aspect explored in this essay: empathy. Suzanne Keen has argued that "the contract of fictionality offers a no-stringsattached opportunity for emotional transactions of great intensity.” But although, as Keen $(2007,168)$ continues, the reader of a novel "may enjoy empathy freely without paying society back in altruism," I would argue that reflections of quality of care and related patient agency in these novels can have a larger cultural and societal impact. This is especially the case where shifts in representations of linguistic capabilities, care environment and cultural memory are enjoined; where reading for the plot is intimately linked to reading for the patient's wellbeing in the present of her condition, not the past held in her memory.

\section{Out of Mind: Psycholinguistic concepts of breakdown and torture of the mind}

Given the popularity among critics and scholars of Out of Mind (e.g. Bitenc 2012, 308-314; Krüger-Fürhoff 2015, 106-108), I here limit myself to exploring what the protagonist's condition looks like. ${ }^{3}$ This is worthwhile because, at around the time of the book's publication, the neurologist Joseph Foley $(1992,30)$ and colleagues asked questions like "What do demented people experience? What does their condition mean to them? What is their reaction to it? What are their gratifications? What are their frustrations?" The scientist saw these questions answered in Out of Mind. In the novel, Maarten Klein is in his 70s when he progressively loses his ability to narrate coherently and to perceive himself as a person. He increasingly loses language; first the ability to speak English, which he had learned after having moved to the United States from the Netherlands after the Second World War, and later the use of the first-person singular pronoun.

Bernlef wrote against the background of the flourishing psycholinguistic approaches to dementia of the time. These approaches, for example, Barry Reisberg's "global deterioration scale (GDS) for age-associated cognitive decline and

3 My reflections on Out of Mind in this essay rely on my previous analysis of Bernlef's text: I explored what Out of Mind reveals about the cultural image of dementia in the mid-1980s, especially focusing on the fictional deployment of dementia for the exploration of post-war trauma at that moment in time (Zimmermann 2020, Ch. 4). 
Alzheimer's disease," were concerned with the worsening of language skills. The different stages defined ranged from "word and name finding deficit[s]" to the point when "all verbal abilities are lost" (Reisberg 1983, 174-175). Placed in this context, Bernlef's novel can be read as pushing the reader to ponder the psycholinguistic implications of denying a patient's continued identity and agency once they can no longer verbally articulate it. Such a reading is particularly meaningful, given the clinical work going on at the time. Towards the end of the 1980s, the most up-to-date scientific publications debated "evidence of awareness and sensitivity” in patients with advanced dementia (Tappen 1988). And contemporary literary critics indeed thought of Maarten Klein as having Alzheimer's disease (Desai 1989).

The question of the experiential side of Maarten's dementia brings us to the role of cultural memory in Out of Mind. Bernlef's narration builds on the medicoscientific understanding that dementia enhances the vividness of long-term memories at the expense of short-term recall (see also Irmela Marei Krüger-Fürhoff's essay on screen memories in this volume). Long-term memories, for Maarten Klein, manifest themselves in dementia-related hallucinations. And these hallucinations make Maarten victim to the most unsettling experiences of his youth, which had been lived in the face of the atrocities committed by Nazi Germany during the occupation of the Netherlands. In the following passage, for example, Maarten imagines himself to be addressing the liberators, voicing a guilty recall of his collaboration with the Nazis. The passage remains ambivalent, as the doctor's administration of a tranquillizer, in Maarten's confused mind, could also be read as Maarten's fear of a Nazi's attempt to kill him: "A man with a square face and short-trimmed hair enters with a syringe in his hand. I try to get off the bed but that blonde one holds me down while I feel the needle jab into my arm. 'I want to live! I want to live!!' 'Don't strap him down,' I hear a man's voice say. [. . . ] Then I suddenly understand everything. 'You've got the wrong man. I wasn't on the wrong side. Maybe I was no hero, but I wasn't on the wrong side. I never hid any fugitives”' (Bernlef 1988, 110). Maarten's dementia is not obviously presented as stemming from his experiences from the Second World War, but Bernlef's choice to connect dementia and the Nazi atrocities, makes the horror of dementia transparent to the reader. Out of Mind thus fuses the depiction of dementia-related psycholinguistic disintegration with the notion of dementia as torture of the mind and - by extension of the German occupation to include the Holocaust - as a death sentence. 


\section{The Madonnas of Leningrad: Empathy for a patient deployed as plot device}

Published in 2006, Debra Dean's debut novel, The Madonnas of Leningrad was a bestseller in the United States. As in Maarten's case, the dementia Dean $(2006,5)$ imposes on 82-year-old Marina enhances long-term memories at the expense of short-term recall - in the words of the invisible narrator, "Whatever is eating her brain consumes only the fresher memories, the unripe moments. Her distant past is preserved, better than preserved. Moments that occurred in Leningrad sixtysome years ago reappear, vivid, plump, and perfumed." This fictionalised disease characteristic, for Dean, is well suited to a composition of two narrative strands. One strand is set in the United States of the present day, as Marina and her husband, Dimitri, prepare for and attend their granddaughter's wedding. The other strand is set in the winter of 1941, during the Siege of Leningrad. As a museum guide in the Hermitage before the war, Marina, during the Second World War, has to join in packing and stowing away the precious artworks so that they may not fall into the hands of the German enemy. As the galleries of the Hermitage gradually empty, Marina begins to "mentally restock[] the Hermitage" (75), to create a "memory palace" (128). Following the principles of mnemonics, she learns by heart the position of each painting in each room and memorises what each painting looks like.

Dean's parallel construction thrives on imagery and experiences shared between past and present. Marina compares the effects of old age on the body, "this withered old carcass" (Dean 2006, 9), to the ravages of the war on "the body she had during the first winter of the siege" (9-10). The short periods of rest between intense hours of packing in the Hermitage are likened to "disappearing for a few moments at a time. Like a switch being turned off. After an hour or so, the switch mysteriously flips again” (5). The same vocabulary depicts Marina's mental absences in her state of dementia (13). The mini mental state examination (MMSE), one of the tools for diagnosing Alzheimer's disease, reminds Marina of school and university exams in her youth - the latter passed "with distinction," while her doctor "was not impressed" (8) with her performance in the former. The MMSE is a battery of tests used to define a patient's stage of cognitive decline; a specific score places the patient in one of the categories of the Global Deterioration Scale, for example. With a maximum possible score of 30 for normally performing individuals, the MMSE score falls with an increasingly steeper decrease over time in the case of Alzheimer's disease.

One further example for concepts shared between the two narrative strands in The Madonnas of Leningrad is the lack of trust of the young in the memory of 
the old. While in 1941, Marina doubts the words of babushka Anya (Dean 2006, 136), the corresponding event in the present turns Marina herself into the object of such doubt, as her daughter-in-law dismisses Marina's recurring ruminations on the past as fictitious, warning Marina's daughter Helen, “I don't know how much credence you want to give everything she says" (102). I will linger on this notion of doubt, because I find it goes beyond how Marina's illness experience is marginalised by others. It extends to the implications of Dean's two-plot strategy for how we, as readers, are led to perceive Marina as lacking agency, particularly in the novel's final chapters.

Using her memory palace to the full, in the last chapter set in the past, Marina gives soldiers a guided tour of the Hermitage. Fully aware of the power of her memory, Marina muses that "without her here to keep the memory of its art alive on the walls, the museum would be merely another decaying shell" (Dean 2006, 174). In the narrative's final, present-day chapter, the reader belatedly becomes aware that Marina has experienced this guided tour in the present day of her imagination. Her visions turn out to be "a gift" (80) that helps her forget the cold as she risks death from hypothermia after having run away from the wedding venue. A construction worker finds Marina in a building site, gesticulating to walls and ceilings and seemingly talking in Russian. Reporting on this, he unknowingly gives credit to the marvel of Marina's memory palace: “'It was like she was saying everything was beautiful. [. . .] You had to be there,' he insisted. 'She was showing me the world"' (228).

The construction worker's statement is available to the reader through Marina's daughter's memory of him. This triangulation explicitly points the reader to the privileged access they have to Marina's memory throughout and as embodied in the past narrative strand. Why is this important? By the time Dean published her narrative, psycholinguistic concepts of breakdown, as explored above, had gradually been replaced by a sociolinguistic focus "on preserved abilities” rather than "decrements and deficits" (Müller and Schrauf 2014, 23). Such discursivist paradigms support continued identity and agency by, for example, explaining a patient's behaviour and assertions in relation to their past experiences - we might think, for example, about Anne Davis Basting's TimeSlips creative storytelling project or the Trebus Project, which captures life stories (Basting 2009, Ch. 11; "Welcome to the Trebus Project”).

Such sociolinguistic understandings are absent from the storying of Marina's dementia. Marina's past and the richness of her memory palace are not accessible to those who care for her, and as such they are not integrated into their perception of Marina's behaviour. More to the point, the reading for notions of loss in this narrative can be taken as the perspective of Marina's daughter or husband, and the novel indeed ends on their point of view: "Marina herself has left, though 
no one is able to pinpoint exactly when that happened, only that at some point she was no longer there. It is all over but the waiting” (Dean 2006, 225).

When a neuropharmacologist like me offers such a reading, she runs the risk - maybe more so than a trained literary scholar - of being exposed to charges that she merely mines this novel for notions of loss, without considering the ethics of readership. Lucy Burke has thought about the ethics of readership in relation to Emma Healey's Elizabeth Is Missing, published in 2014. Healey's account, in many ways, is comparable to Dean's (Zimmermann 2020, Ch. 7). Also a debut novel and a bestseller, the novel features an older, progressively declining dementia patient. ${ }^{4}$ Healey's novel, too, is composed of two narrative strands: one set in the present day of Maud's increasing memory loss, one evolving around the disappearance of Maud's sister Sukey after the war. The mystery is solved by Maud's digging in her friend Elizabeth's garden. The people in Maud's environment attribute this behaviour to her dementia, but in fact it leads Helen to discover Sukey's body. For Burke, Elizabeth Is Missing "tells a story about ways of thinking about and living with dementia in a fundamentally inhospitable culture" $(2018,96)$. And similarly, Sarah Falcus and Katsura Sako describe the novel as "drawing attention to the social environment which judges and isolates those with dementia" (2019, 130).

To make a similar reading work for Dean's novel, we have to assign to the reader's agency a process of learning that ensures, as Burke puts it, the "ethical recognition of a person with dementia” $(2018,99)$. This learning is not an easy task in Dean's novel, even if the reader were to read for a meaningful merger of the two narrative strands. This is partly explained by how the separating out of two strands plays into notions of disruption. And these, in turn, are strongly underpinned by the role of cultural memory in this novel. In fact, the parallel construction attunes the reader actively to look for war-related language shared by the two strands like the comparison of the nursing home to the death camp (Dean 2006, 46). The close knitting together of dementia and Nazi horror resonates with, and thereby enhances, psycholinguistic concepts of breakdown, as when we become privy to Marina's experience that "her thoughts seemed to move through sludge, words falling away, whole sentences lost in the muck. The paintings themselves seemed to be disintegrating, shot through with light and shadow like leaves eaten into lace by insects" (177). To put it simply, for the plot set in the past to move forward, Marina's dementia has to progress, her brain has to "empty." Marina, in fact, thinks of

4 It is not explicitly mentioned that Maud has "dementia” or "Alzheimer's disease." But the 82year-old's forgetfulness is typified in situations and scenes that pertain to the cultural mainstream as far as age-related dementia is concerned (like going to the shops and forgetting why one went, not remembering how to lay the dinner table, or mistaking close relatives for strangers). 
herself as "becoming like the museum. Everything, it is leaking. It is horrible" (96). But why does dementia feature in Dean's novel at all? Why not set the narrative in wartime Leningrad in the first place? After all, it is the plot set in the past that we read it for. To think through this question, I will first take a closer look at the composition of a third text, Alice LaPlante's Turn of Mind.

\section{Turn of Mind: A piece of detective fiction or a case study of cognitive decline?}

Turn of Mind, published in 2011, deals with 74-year-old Amanda O’Toole's mysterious death. Particularly disconcerting in this fictional detective case is that four fingers from Amanda's right hand have been surgically removed after rigor mortis had set in. Chief suspect is 64-year-old Jennifer White, a retired hand surgeon and Amanda's long-term friend and neighbour. Yet, Jennifer has been diagnosed with Alzheimer's disease, and her MMSE cognitive rating scale of 19 out of 30 makes it seem impossible that she could strategically plan, execute and cover up such a crime.

LaPlante's novel is entirely organised by the motif of dementia - on the level of story, text and narrative. The text is split into four parts, each shorter than the previous one - with plot time initially decreasing by a third and, in the final part, tumbling to only a quarter of the section before. Like Out of Mind, it is told in short paragraphs of varying decreasing length. Matching the textual indicators of decline, these four parts are set in different locations. In Part 1, Jennifer still lives in her own house. Part 2, by comparison, is set in a nursing home - described by Jennifer as "the descent from one circle of hell into the next” (LaPlante 2011, 143). Such a change in setting, if we follow Constance Rooke on the home in fiction, signals Jennifer's imminent loss of self and identity in society (1992, 255). This becomes reality in Part 3, when Jennifer escapes the nursing home and the narrative traces her inability to interact adeptly with the outside world. Part 4 takes the reader into a prison-like public nursing facility.

Any murder mystery centrally relies on plot. ${ }^{5}$ "Everything in the story's structure," writes Peter Brooks, "and its temporality, depends on the resolution of enigma” (1984, 18). Jennifer's move to the nursing home helps thicken the plot. It also brings out the conceptual connection between Turn of Mind and

5 For deliberations on the role of detective fiction in dementia discourse developments, see Zimmermann (2020, Ch. 6). 
literary texts that refer to the Holocaust. Maarten Klein confuses being placed in a nursing home with being deported, Dean's narrator compares the care home to the death camp and Jennifer wonders in conversation with the resident manager Laura, "What did you do [to get sent here]? Everyone here has committed a crime. Some worse than others" (LaPlante 2011, 155). The nursing home as a locus of confinement merges notions of disease and crime, detention and punishment. This means that the patient is treated like a criminal. But a key characteristic of a criminal (as well as of a detective) is the ability to plot. It is this genre-required in/ability to plot that makes Turn of Mind a page-turner. From the first moment, when Jennifer is being interrogated by the police, the narrative is focalised through her only. The reader permanently lives under the horizon of her perspective and perception. Jennifer is both actor and witness, and therefore has control over what is revealed. This means that the reader reads not only for the question of whodunit but also against the trajectory of the disease, hoping that the mystery will be solved before Jennifer's condition deteriorates further. In this regard, the continuous shifts in location have two functions in the novel because the effect is one of confusion: they work for Turn of Mind as a piece of detective fiction as much as a case study of dementia. How exactly does this play out?

A detective novel "is created [. . .] in four movements," writes Robin Winks: (i) confronting the problem; (ii) looking for evidence; (iii) assessing the evidence; and (iv) revealing the identity and motivation of the criminal $(1988,7)$. In Turn of Mind, these four movements are connected to four different settings and stages of Jennifer's condition. Thus, the continuous change of location increases tension as it pushes towards discovering evidence and draws the reader in the direction of dénouement, while tracing Jennifer's decreasing cognitive capabilities and agency. This effect is enhanced as Jennifer's felt space continuously shrinks. Space, according to the philosopher Hermann Schmitz and his co-authors Rudolf O. Müllan and Jan Slaby, "is not originally encountered as the measurable, locational space assumed in physics and geography, but rather as a predimensional surfaceless realm manifest to each of us in undistorted corporeal experience, for example in [. . . ] sensing atmospheres" (2011, 245). "These atmospheres," writes Mathias Wirth about Schmitz's theory of feelings, “corporeally affect patients, doctors, nurses, and relatives" (2018, 4). ${ }^{6}$ In Turn of Mind, they also affect the detective and her view of Jennifer - as witness or criminal.

6 I am indebted to Brian Hurwitz for pointing me to the work of Hermann Schmitz and Mathias Wirth. 
Initially, we are encouraged to believe in Jennifer's authority as conferred upon her by the detective, the chief integrative figure of a mystery. The inspector trusts the continued power of Jennifer's mind to solve the crime: "I want your brain. I need your brain” (LaPlante 2011, 161), she asserts. But when story and text both play into mainstream understandings of dementia as a relentless process of degeneration resulting, for instance, in the loss of agency and wits, trusting Jennifer's continued capabilities means hard work for the reader. A steadily shifting narrative perspective suggests that Jennifer, in fact, does lose the ability to plot - and by this I mean both her ability to follow a sequence of everyday activities and her ability to scheme or intrigue. Told in the first person, only Part 1 truly suggests the presence of a plotting individual (Brooks 1984, 114). Part 2, although still told in the first person, attends already much more to Jennifer's shrinking felt space, her sensory and visceral experiences. Plotting, for Jennifer, becomes the most rudimentary process of survival; in her own words: "When I have a clear day [. . .] I plot. I am not good at it. [. . .] My plots are simple." What follows is a list of most elementary activities: "Walk to the door. Wait until no one is looking. Open the door. Leave. Go home. Bar the front entrance against all comers" (LaPlante 2011, 187). With the beginning of the narrative's third part, the first-person pronoun disappears. Reminiscent of Bernlef's narrative strategies, the story is now told in the second person.

Part 4 is written in the third person. But, unlike in Bernlef's Out of Mind, this third-person perspective does not easily admit the reader into the patient's world of experience in free indirect style. The reader constantly wonders whether the text traces Jennifer's experience from within - or whether we are entrusted to an invisible, omniscient narrator. This confusion brings home the power of the narrative perspective in LaPlante's mystery: “An internal perspective,” as Keen writes, "best promotes character identification and readers' empathy" (Keen 2007, 96; see also Strauß 2017, 89). ${ }^{7}$ Such an internal perspective is best achieved through first-person self-narration or figural narration. Narration that moves inside many characters (as in Dean's account, where the narration moves from Marina to her husband to her daughter and back) creates distance. The instability of the narrative perspective in the final part of Turn of Mind then raises two questions: first, how well we could follow the patient up until this point; and second, how disease-imposed changes distance character from reader. The reader might wonder what has happened in the story so that LaPlante can confidently make this narrative choice in the final part.

7 I am indebted to Heike Hartung for pointing me to Sara Strauß's book chapter on Alice LaPlante's Turn of Mind. 
At the end of Part 3, the inspector is convinced she has solved the mystery. For her, Jennifer has killed Amanda, and Jennifer's daughter Fiona has covered up the crime. Jennifer is transferred to a public nursing facility where she will stay for the remainder of her living days. Here, in Part 4, we find ourselves listening to Fiona, as she tells her mother how grateful she will always be that Jennifer covered up her manslaughter. With the mystery being solved, access to the patient's mind is no longer needed. In the words of LaPlante's narrator, "But when all is done, when the end is near, what is left? What is one left with? Physical sensation [. . . ]. Now that it is over, now that it's near the end, she can think. She can allow herself to drift to places that before she would not go" $(2011,297)$. Put differently, dementia is allowed to progress to yet another stage - or, as Dean's narrator puts it in relation to Marina, "It is all over, but the waiting."

As the reader closes the novel, a nagging realisation remains. Yes, Jennifer serves as not much more than a listening vessel in Part 4, and one could argue that, as a patient, Jennifer simply makes for an extremely suitable unreliable narrator in what is designed as a gripping read. This impression is enhanced by how, as Falcus and Sako observe, the "interactions between the characters are described in the text without much of Jennifer's interpretative commentary, like lines in the transcript of a play, suggesting her lack of cognitive and emotional response to what she hears and sees" (2019, 133-134). However, the patient as criminal reveals herself as a red herring on several counts. We remain unclear about how much Jennifer actually plotted herself. We also realise that the patient truly led on inspector and reader - even when she is no longer able to act as a witness; the shift in narrative voice "achieves a distancing effect from the protagonist [so that] the reader calls Jennifer's complete innocence into question" (Strauß 2017, 100). And Jennifer's condition ensures that the crime committed by her daughter will remain unpunished forever. In the end, Jennifer's agency is an illusion - her actions are determined by the progression of her disease - it is her disease-imposed silence that protects her daughter. Or as Jennifer muses early on: "I wonder what will remain in my mind, at the end. What basic truths will I return to? What tricks will I play and on whom?” (LaPlante 2011, 74). These words resonate both with the condition itself and the mystery at hand.

LaPlante exploits psycholinguistic notions of breakdown to create the most unreliable narrator possible in fiction; she mercilessly traces Jennifer's “death of the mind" (LaPlante 2011, 136). But, in following Jennifer's decline and reading for the question of whodunit, we exercise sociolinguistic thinking: we constantly piece together what remains - in terms of narrative capabilities and the presumable reliability of Jennifer's mind. This kind of reading for the plot, I would argue in reliance on Michael Bérubé (2018, 135), prevents the reader 
"from reading right past the text to the 'content' within"; and by content, Bérubé means a diagnostic reading that focuses on the question of accuracy of the representation of a person with dementia. ${ }^{8}$ This readerly activity elevates Jennifer from the rank of a cardboard figure typically required by the genre to a character with agency; an activity, as Pieter Vermeulen argues in this volume, that perhaps accords dementia a moral privilege. Concurrently, given that the action takes place in the here and now of Jennifer's illness, this activity frees the patient from what a long history of memory politics in dementia fiction has created: the idea of the patient as living in the past and on an emptying memory. Unlike in The Madonnas of Leningrad, dementia in Turn of Mind does not serve as an access point to a separate storyline in and of the past. Everything of interest to the reader happens in the present. Where the story needs the past, it is accessed through Jennifer's diary-like notebook (from which a page apparently holding a clue has been excised). A common therapeutic intervention in cases of dementia, this fictional diary includes information entered by visitors for Jennifer to read when she has "a better day" (e.g. Silva et al. 2017). For the reader (as well as the detective), the notebook works as an interface between perceived reliability and supposed cognitive impairment, between past and present.

At a recent Dementia, Narrative and Culture Network workshop for academics and service users, Veronica Franklin Gould, president and head of research at Arts 4 Dementia, emphasised how arts interventions re-energise people despite their early dementia symptoms - and here we are compelled to think of Marina's revival in the final chapter of Dean's novel (Gould 2018). Gould particularly stressed the power of living and interacting with the patient in the present and ranked these activities much higher than reminiscence strategies that keep the patient in the past of their not necessarily happy long-term memories.

\section{The politics of memory in the literary history of dementia fiction}

Bernlef's Out of Mind enmeshes dementia with notions of trauma, war and extinction at a time when the 40th anniversary of the end of war in Europe was being commemorated. This move introduced the disease as a metonym for memory loss and forgetting, and, as the essays collected in this volume suggest, this link endures to the present day. It contributes to negative characterisations of persons

8 I owe thanks to James Rákóczi for telling me about Michael Bérubé’s work. 
living with dementia, with pessimistic views of the patient impacting on the kind and quality of care provided, which have found reflection in subsequent fictional representations of dementia. As the victim of a veritable death sentence (which does not leave any room for agency), the patient turned into a narrative prosthesis from the 1980s onwards (Zimmermann 2017a, 83-85). ${ }^{9}$ Twenty years after Bernlef's intervention, Debra Dean's Marina suffers the consequences of this pessimism about ageing, as her relatives do not believe she can tell her own story (and her agency to remember in the Hermitage is valorised as an activity of the young Marina). For Alice LaPlante's Jennifer the situation is slightly better - perhaps also because, at 64 years old, she is notably younger than the other two characters. The detective believes in her continued capabilities - and, as the one through whom Turn of Mind is focalised, she in fact controls the plot.

The idea of 'losing the plot' has become central to how society pitches the dementia patient in the literary imagination. At least in part, this can be traced to the period of the memory boom, when caregivers, for example, pictured their loved ones as losing their personalities because they were losing awareness of their painful and identity-defining past. Out of Mind emerges from this period. It negotiates the contemporary notion, as explored by Paul John Eakin, that serious impairment of the ability to tell or understand stories severely impacts on our sense of self (1999, 46; Zimmermann 2017b, 7-12). Dean develops this further. The perceived absence of a functioning memory leads others to doubt the patient's continued identity, a perspective reflected in how Marina's condition remains a vehicle for telling a story set in the past. Dean's choice appears particularly problematic when placed in conversation with Bernlef's narrative experiment and LaPlante's murder mystery. Out of Mind narrates the experience of dementia exclusively from within the patient's mind, necessitating the reader's belief in Maarten as narrator with a continuous identity. The process of reading itself ensures Maarten's authority and agency. During the period of Alzheimerisation, Out of Mind was arguably the first and most prominent piece of fiction to explore what dementia might feel like from within, leaving readers "with what we think dissolution of memory and breakdown of language may feel and look like” (Krüger-Fürhoff 2015, 108). It established the narrative techniques that have since been used again and again to portray the patient's supposed loss of articulacy and agency, identity and self.

9 I am adapting this term from David T. Mitchell and Sharon L. Snyder (2000, 6), who use it to emphasise that "the prosthesizing of [. . . ] a rhetorical figure carries with it ideological assumptions about what is aberrant." 
In addition, Bernlef popularised the fact that dementia enhances the vividness of long-term memories at the expense of short-term recall. Exploring the patient's past has since turned into an essential element of dementia fiction; eventually, as in The Madonnas of Leningrad, it became a narrative device. Although issues of cultural context are beyond the scope of this essay, the atrocities committed by Nazi Germany are forever etched into cultural and political memory and thus taken up by writers from around the world, not just those from Europe. We do not need actively to invest in Marina's continued identity to gain access to her past. What is more, by reading under the oppressive horizon of war-related metaphorical concepts and experiences, the reader's agency might easily fulfil what Dean's construction is able to challenge: we might miss the precious insight to be gained from how the two narrative strands meaningfully come together; we might miss Marina's continued rich inner life and experience. We might miss how identity-denying, extermination-related imagery keeps directing notions of loss which continue to dominate the current cultural dementia narrative.

Turn of Mind can be taken as proof of this. In the twenty-first century, a murder mystery may be the genre of choice for subjects that everybody wants to understand but cannot: the dementia experience. In the final pages of Out of Mind, Bernlef's Maarten Klein experiences freedom, freedom from the disease through his death (and freedom from the Nazi occupation of his mind). Jennifer, by comparison, loses her freedom. Yet she remains the winner in the hide-andseek between detective and murderer - in a narrative told entirely in and about the present of Jennifer's illness. Until the narrative's final lines, Turn of Mind plays on the question of what this story is about - the careful tracing of a mind in dissolution or the dismantling of a crime. And this continued and persistent tension explains the power of LaPlante's text. Turn of Mind forces the reader to stay with the crime at hand, while kindling empathy for a patient increasingly challenged by the consequences of cognitive decline. Thinking in terms of genre, the plot-reliant detective story can return agency to the patient. But it does so more effectively when removed from the oppressive discourse of war-related extermination terminology, in a narrative space that privileges what Schmitz et al. (2011, 245) term the "affective involvement" of the person with dementia, in this way freeing the patient from being deployed as a narrative device without agency, while opening avenues for more supportive and enabling approaches to care. 


\section{References}

Adelman, Richard C. “The Alzheimerisation of Aging." Gerontologist 35 (1995): 526-532.

Basting, Anne Davis. Forget Memory: Creating Better Lives for People with Dementia. Baltimore: Johns Hopkins UP, 2009.

Bernlef, J. [Hendrik Jan Marsman]. Out of Mind. 1984. Trans. A. Dixon. London: Faber and Faber, 1988.

Bérubé, Michael. The Secret Life of Stories: From Don Quixote to Harry Potter, How Understanding Intellectual Disability Transforms the Way We Read. New York: New York UP, 2018.

Bitenc, Rebecca A. "Representations of Dementia in Narrative Fiction." Knowledge and Pain. Ed. Esther Cohen, Leona Toker, Manuela Consonni and Otniel E. Dror. Amsterdam: Rodopi, 2012. 305-329.

Brockmeier, Jens. Beyond the Archive. Memory, Narrative, and the Autobiographical Process. New York: Oxford UP, 2015.

Brooks, Peter. Reading for the Plot. Design and Intention in Narrative. Cambridge, MA: Harvard UP, 1984.

Brooks, Peter. The Melodramatic Imagination: Balzac, Henry James, Melodrama, and the Mode of Excess. New Haven, CT: Yale UP, 1995.

Burke, Lucy. "Missing Pieces: Trauma, Dementia and the Ethics of Reading in Elizabeth Is Missing." Dementia and Literature: Interdisciplinary Perspectives. Ed. Tess Maginess. Abingdon: Routledge, 2018. 88-102.

Dean, Debra. The Madonnas of Leningrad. 2006. London: Harper Perennial, 2007.

Desai, Anita. “The Narrator Has Alzheimer's." New York Times, 17 September 1989.

Eakin, Paul John. How Our Lives Become Stories: Making Selves. Ithaca, NY: Cornell UP, 1999.

Falcus, Sarah, and Katsura Sako. Contemporary Narratives of Dementia: Ethics, Ageing, Politics. Abingdon: Routledge, 2019.

Foley, Joseph M. “The Experience of Being Demented.” Dementia and Aging: Ethics, Values, and Policy Choices. Ed. Robert H. Binstock, Stephen G. Post and Peter J. Whitehouse. Baltimore: Johns Hopkins UP, 1992. 30-43.

Gould, Veronica Franklin. "Reawakening the Mind: Arts Interventions to Re-energise People above Early Symptoms of a Dementia and Their Carers." Paper presented at the workshop "Working Together: Collaboration beyond the Academy in Research in Dementia and Culture," Senate House London, 23 November 2018.

Healey, Emma. Elizabeth Is Missing. 2014. London: Penguin Books, 2015.

Huyssen, Andreas. Introduction. Present Pasts. Urban Palimpsests and the Politics of Memory. Stanford, CA: Stanford UP, 2003. 1-29.

Keen, Suzanne. Empathy and the Novel. New York: Oxford UP, 2007.

Krüger-Fürhoff, Irmela Marei. "Narrating the Limits of Narration: Alzheimer's Disease in Contemporary Literary Texts." Popularizing Dementia: Public Expressions and Representations of Forgetfulness. Ed. Aagje Swinnen and Mark Schweda. Bielefeld: Transcript, 2015. 93-112.

LaPlante, Alice. Turn of Mind. London: Harvill Secker, 2011.

Mitchell, David T., and Sharon L. Snyder. Narrative Prosthesis: Disability and the Dependencies of Discourse. Ann Arbor: University of Michigan Press, 2000. 
Müller, Nicole, and Robert W. Schrauf. "Conversation as Cognition: Reframing Cognition in Dementia." Dialogue and Dementia: Cognitive and Communicative Resources for Engagement. Ed. Robert W. Schrauf and Nicole Müller. New York: Psychology Press, 2014. 3-26.

Ramanathan, Vai. Alzheimer Discourse: Some Sociolinguistic Dimensions. Mahwah, NJ: Lawrence Erlbaum, 1997.

Reisberg, Barry. "Clinical Presentation, Diagnosis, and Symptomatology of Age-Associated Cognitive Decline and Alzheimer's Disease.” Alzheimer's Disease: The Standard Reference. Ed. Barry Reisberg. New York: The Free Press, 1983. 173-187.

Rooke, Constance. "Old Age in Contemporary Fiction: A New Paradigm of Hope." Handbook of the Humanities and Aging. Ed. Thomas R. Cole, David D. Van Tassel and Robert Kastenbaum. New York: Springer, 1992. 241-257.

Schmitz, Hermann, Rudolf O. Müllan and Jan Slaby. "Emotions Outside the Box - the New Phenomenology of Feeling and Corporeality." Phenomenology and the Cognitive Sciences 10 (2011): 241-259.

Silva, Ana Rita, Maria S. Pinho, Luís Macedo, Christopher Moulin, Salomé Caldeira and Horácia Firmino. "It Is Not Only Memory: Effects of Sensecam on Improving Well-Being in Patients with Mild Alzheimer Disease." International Psychogeriatrics 29 (2017): 741-754. Strauß, Sara. "Narrative Ethics and Dementia in Alice LaPlante's Turn of Mind." Dementia and Subjectivity: Aesthetic, Literary and Philosophical Perspectives. Ed. Daniela Ringkamp, Sara Strauß and Leonie Süwolto. Frankfurt am Main: Peter Lang, 2017. 89-104.

Tappen, Ruth M. “Awareness of Alzheimer Patients.” American Journal of Public Health 78 (1988): 987-988.

Trebus Project. "Welcome to the Trebus Project.” www.trebusprojects.org/ (September 2019). Winks, Robin W. Introduction. Detective Fiction: A Collection of Critical Essays. Ed. Robin W. Winks. Woodstock: Countryman Press, 1988. 1-14.

Wirth, Mathias. "Phenomenology and Its Relevance to Medical Humanities: The Example of Hermann Schmitz's Theory of Feelings as Half-Things.” Medical Humanities (2018): 1-7.

Zimmermann, Martina. "Alzheimer's Disease Metaphors as Mirror and Lens to the Stigma of Dementia." Literature and Medicine 35 (2017a): 71-97.

Zimmermann, Martina. The Poetics and Politics of Alzheimer's Disease Life-Writing. Basingstoke: Palgrave Macmillan, 2017b.

Zimmermann, Martina. The Diseased Brain and the Failing Mind. Dementia in Science, Medicine and Literature of the Long Twentieth Century. London: Bloomsbury, 2020. 